\title{
Supporting Indigenous communities during environmental public health emergencies
}

\author{
Angela Eykelbosh*, Chief Marilyn Slett ${ }^{\dagger}$, Pamela Wilson $^{\dagger}$, Linda Pillsworth ${ }^{\ddagger}$, Gethsemane Luttrell ${ }^{\ddagger}$, David Reid ${ }^{\ddagger}$ \\ "National Collaborating Centre for Environmental Health, Vancouver, BC, Canada \\ +Heiltsuk Tribal Council, Bella Bella, BC, Canada \\ *First Nations Health Authority, Vancouver, BC, Canada
}

\section{Background}

Environmental health practitioners are often called upon to support communities during environmental public health (EPH) emergencies, providing typical services under atypical conditions as well as addressing the unique needs of the community during a stressful time. In Indigenous communities, EPH disasters may impact the population in ways distinct from those of non-Indigenous communities and may require a very different approach. Some of the factors that may result in an Indigenous community being differentially or even disproportionately impacted include:

- Logistical difficulties in providing emergency services to remote or isolated communities.

- Variability in local administrative and technical capacity that may hinder active participation in response and recovery operations.

- Lack of trust, a legacy of colonialism that may affect coordination or collaboration during the response, and which may impact the utilization of health services.

- Reliance on local ecosystems for food and other resources necessary for economic, socio-cultural, spiritual, and physical well-being. The ability to maintain cultural practices through interaction with the natural environment is a critical determinant of health in Indigenous communities (Richmond and Ross, 2009).

- The existence of profound social and health inequities that may leave Indigenous communities more vulnerable to mental or physical health impacts and (or) less able to respond (Loppie Reading and Wien, 2009).

Mental health and community impacts among Indigenous Alaskan communities were explored in detail during and after the Exxon Valdez oil spill in Prince William Sound, Alaska. At the individual level, Indigenous persons who were directly impacted by the spill were more likely to show clinical indicators of depression compared with their non-Indigenous (Euro-American) neighbours one year after the spill (Palinkas et al., 1992). Among Indigenous Alaskans, depression scores were significantly associated with having participated in clean-up and having experienced impacts on hunting, fishing, and gathering activities; these impacts were more severe among women (Palinkas et al., 1992). Being exposed to the spill was also associated with social disruption, as

Corresponding author: Angela Eykelbosh (email: angela.eykelbosh@ bccdc.ca). manifested by a decline in the quality of interactions within families and among friends, greater conflict with outsiders, and less involvement overall in community activities (Palinkas et al., 1993). Spill-related social disruption was also associated with indicators of post-traumatic stress among Native Alaskans (Palinkas et al., 2004). Because the spill also affected traditional activities related to marine resources, the spill furthermore contributed to cultural erosion (Dyer, 1993; Miraglia, 2002).

More recently, on BC's central coast, the sinking of the Nathan E. Stewart and subsequent leak of more than 235,000 L of marine diesel fuel into Seaforth Channel resulted in widespread impacts to the Heiltsuk people. ${ }^{1}$ These impacts included physical and mental health impacts related to exposure to the spilled fuel as well as community members' intensive efforts in the clean-up over a 6-week period leading to stress and exhaustion. Because the spill occurred in a key clam harvesting area just before the opening of the commercial fishery, the spill also affected food provision and livelihoods of numerous community members (Heiltsuk Tribal Council, 2017; Slett et al., 2016).

In addition to the primary mental, physical, and community impacts of an EPH disaster, communities may also be subject to secondary traumas related to the response and (or) recovery. During the Exxon Valdez disaster, Indigenous Alaskan communities reported a sense of intrusion and loss of privacy due to repeated contact with well-meaning researchers, tourists, and fact-finding missions wishing to learn from the Exxon Valdez event (Miraglia, 2002). The communities also suffered from chronic stress related to the drawn-out legal process necessary to determine compensation and intra-community conflict regarding how those resources should be fairly distributed (Miraglia, 2002; Picou et al., 2004). In the case of the Nathan E. Stewart, the release of marine diesel fuel into traditional food harvesting areas created long-term fears for food safety and sustainability of the resource (Heiltsuk Tribal Council, 2017; Slett et al., 2016). Although difficult to anticipate, stressors such as these can negatively impact the long-term well-being of a community and its people.

\section{How can we help?}

Environmental health professionals can help to reduce the impact of EPH disasters on Indigenous communities by supporting them throughout the response and recovery. The suggestions below are drawn from the professional and personal experiences of the authors during the Nathan E. Stewart spill and other events. 


\section{A respectful beginning}

Public health interaction with Indigenous communities is a nation-to-nation engagement. Recognizing communities' Indigenous rights and title, their right to self-governance, and committing to a respectful, transparent partnership is crucial to this engagement. This includes shared decision-making and respect for cultural protocols and traditional law. Issues may arise when working within the incident command system (ICS), as the ICS command-and-control structure may be inconsistent with community values regarding consensus decision-making and seeking community input. Furthermore, externally imposed decision-making or a sense of loss of control may be reminiscent of previous harmful policies toward Indigenous communities and may trigger secondary trauma. A proven best practice is to align response efforts with local leadership immediately, including establishing a point of contact (individual or group), and creating space for community participation.

\section{Engage local capacity}

Priorities for environmental health or health impact assessment may not be immediately apparent. Indigenous communities hold considerable local knowledge of their territories and in many cases deliver various services to their community members including health services, lands and resource management, and economic development. Recognizing and incorporating this expertise to identify and understand potential impacts during the response and recovery is essential.

\section{Engage external partners}

In the event of a health emergency, various health agencies may be involved to provide support and health care services in Indigenous communities. These include Health Canada's First Nations and Inuit Health Branch (FNIHB); First Nations Health Services Organization, a legal entity that employs health staff to deliver services to member First Nations, such as a health service society or health council; and regional or provincial public health authorities. In BC, First Nations Health Authority assumed responsibility for the programs and services previously delivered by FNIHB-Pacific Region in 2013.

\section{Information gathering}

If health information is collected, the data collected and the means used to obtain it should be tailored to the community. For example, health assessment and surveillance tools intended for a large urban population may not adequately capture impacts to a remote Indigenous community. Privacy of the individual and the community must be protected through detailed discussion of information-sharing arrangements and should meet the principles of Ownership, Control, Access, and Possession. ${ }^{2}$

Vulnerable populations may require additional consideration, including children and the elderly. In particular, community members who have been engaged in clean-up work may experience more severe physical impacts due to direct exposure, including toxic effects, injuries, and exhaustion, as well as mental or emotional strain (Eykelbosh, 2014). Negative effects may also extend to those indirectly involved through impacts to traditional food sources or critical industries for local employment.

Health risk communication must adequately address the specific concerns of the community and be delivered in a manner that reaches various audiences within the community. Consideration may be needed for language translation, door-todoor delivery, and various media products. Timely and accurate information from trusted sources may assist in reducing anxiety.

\section{Devising an effective and culturally appropriate response}

A culturally appropriate response is one that occurs with the consent of the community and that incorporates Indigenous ways and means of healing. Cultural healing practices, which make use of ceremony, ritual, and fellowship, are critical to promoting health and wellness in Indigenous communities (Kirmayer et al., 2003). Enlisting the aid of cultural service providers or cultural knowledge keepers may help to incorporate traditional knowledge and cultural healing into interventions.

\section{Following through to recovery}

Environmental health practitioners have a role to play in assisting Indigenous communities to identify, understand, and cope with the long-term health impacts of oil spills. Evaluating impacts to traditional food resources may require a great deal of time and effort, and should consider the unique consumption patterns of each community; adequate nutritional replacement may be necessary. Loss of access to cultural sites and recreational opportunities enhance the risk of cultural erosion after a severe disturbance. Because mental health impacts of such disasters may not peak until long after the event (Norris and Elrod, 2006), the need for expanded mental health services may be prolonged.

Practitioners may also assist communities in developing a long-term recovery action plan, which is a forward-looking exercise that assists the community to: $(i)$ set objectives for recovery, (ii) devise community-based projects to achieve those objectives, (iii) target resources accordingly, (iv) identify indicators of success, $(v)$ conduct periodic assessments to chart progress, and ( $v i$ ) transition back to normalcy (Flood Recovery Task Force, 2013). Although such plans typically address many aspects of recovery, they can be scoped to focus on general or specific health impacts, including mental health impacts, as is currently underway in the recovery of Lac-Mégantic after the 2013 train derailment disaster (Bouffard et al., 2017; Généreux et al., 2014).

\section{Summation}

Environmental health professionals play a critical role in supporting communities through disasters. Although we have focused on fuel spills, the recommendations provided here may be helpful in supporting Indigenous communities dealing with other incidents or emergencies impacting their traditional territories. How a community can be best supported can only 
be determined through consultation and in the case of Indigenous communities these needs may be shaped by cultural, historical, geographic, and other factors. Although the potential for differential or disproportionate impacts exists, respectful, genuine, and committed engagement with Indigenous communities can help to lessen the likelihood of these impacts.

\section{Notes}

1. For a visual depiction of Heiltsuk territory, please visit http://www. heiltsuknation.ca/about-2/territory/

2. The OCAP principles refer to the accepted standard by which information collected in Indigenous communities should be collected, protected, used and shared. More information can be found at: http://fnigc.ca/ocap.html

\section{References}

Bouffard, C., Clusiault, C., Gosselin, J., Lalonde, G., Maillet, M.C., Nault-Horvath, E., Stewart, C., and Généreux, M. 2018. A few initiatives to mobilize the local community in a post-disaster landscape. Centre intégré universitaire de santé et de services sociaux de l'Estrie - Centre hospitalier universitaire de Sherbrooke, Province of Quebec.

Dyer, C.L. 1993. Tradition loss as secondary disaster: Long-term cultural impacts of the Exxon Valdez oil spill. Sociol. Spect. 13(1): 65-88 doi: 10.1080/02732173.1993.9982017

Eykelbosh, A.J. 2014. Health effects of oil spills and implications for public health planning and research. Vancouver, BC: National Collaborating Centre for Environmental Health (NCCEH).

Flood Recovery Task Force. 2013. Municipal recovery toolkit. Government of Alberta. Available at: http://aep.alberta.ca/ water/programs-and-services/flood-mitigation/flood-mitigation-236.693 ptprojects/documents/MunicipalRecoveryToolkitOct28-2013.pdf. [Accessed 12 January 2018.]

Généreux, M., Petit, G., Maltais, D., Roy, M., Simard, R., Boivin, S., Shultz, J.M., and Pinsonneault, L. 2014. The public health response during and after the Lac-Mégantic train derailment tragedy: A case study. Disaster Health. 2(3-4): 113-120.
Heiltsuk Tribal Council. 2017. Investigation report: The 48 hours after the grounding of the Nathan E. Stewart and its oil spill. Available at: http://www.heiltsuknation.ca/wp-content/uploads/2017/10/ HTC-NES-IRP-2017-03-31.pdf. [Accessed 12 January 2018.]

Kirmayer, L., Simpson, C., and Cargo, M. 2003. Healing traditions: Culture, community and mental health promotion with Canadian Aboriginal peoples. Aust Psychiatry. 11: S15-S23. doi: 10.1046/j.1038-5282.2003.02010.x

Loppie Reading, C., and Wien, F. 2009. Health inequalities and social determinants of aboriginal peoples' health. National Collaborating Centre for Aboriginal Health. Available at: https://www.ccnsa-nccah.ca/docs/determinants/RPT-HealthInequalities-ReadingWien-EN.pdf. [Accessed 27 February 2018.]

Miraglia, R.A. 2002. The cultural and behavioral impact of the Exxon Valdez Oil Spill on the native peoples of Prince William Sound, Alaska. Spill Sci. Technol. Bull. 7(1): 75-87. doi: 10.1016/ S1353-2561(02)00054-3

Norris, F.H., and Elrod, C.L. 2006. Psychosocial consequences of disasters: A review of past research In F.H. Norris, S. Galea, M.J. Friedman, and P.J. Watson (Eds.), Methods for disaster mental health research. New York: Guilford Press, pp. 20-42.

Palinkas, L.A., Downs, M.A., Petterson, J.S., and Russell, J. 1993. Social, cultural, and psychological impacts of the Exxon Valdez oil spill. Hum. Organ. 52(1): 1-13. doi: 10.17730/humo.52.1.162688w475154m34

Palinkas, L.A., Petterson, J.S., Russell, J.C., and Downs, M.A. 2004. Ethnic differences in symptoms of post-traumatic stress after the Exxon Valdez oil spill. Prehosp Disaster Med. 19(1): 102-112. doi: 10.1017/S1049023X00001552

Palinkas, L.A., Russell, J., Downs, M.A., and Petterson, J.S. 1992. Ethnic differences in stress, coping, and depressive symptoms after the Exxon Valdez oil spill. J. Nerv. Ment. Dis. 180(5): 287-295. doi: 10.1097/00005053-199205000-00002

Picou, J.S., Marshall, B.K., and Gill, D.A. 2004. Disaster, litigation, and the corrosive community. Soc. Forces. 82(4): 1493-1522. doi: $10.1353 /$ sof.2004.0091

Richmond, C. A. and Ross, N. A. 2009. The determinants of First Nation and Inuit health: A critical population health approach. Health Place. 15(2): 403-411. doi: 10.1016/j.healthplace.2008.07.004

Slett, M., Pillsworth, L., and Eykelbosh, A.J. 2016. Community impacts of fuel spills: A case study from BC's Central Coast. Vancouver, BC: National Collaborating Centre for Environmental Health. 